\title{
Methods of redundant schemes and software for optimization of heat source structure
}

\author{
Olga A. Edeleva. ${ }^{1,}{ }^{*}$, Evgeny A. Barakhtenko, Dmitry .V. Sokolov ${ }^{1}$ \\ ${ }^{1}$ Melentiev Energy Systems Institute SB RAS, 130 Lermontov Str., Irkutsk, 664033, Russia
}

\begin{abstract}
The optimization of heat sources in populated areas is associated with the optimization of their structure. The optimization problem is of linear discrete nature and is hard to formalize [1]. The aim of the optimization is to identify the types, sites and mix of equipment of the heat sources. Moreover, this optimization problem is closely related to the scheme and parameter optimization since the equipment mix of heat sources and their connection to existing (newly constructed) consumers determine the heat network configuration. The emerging new trends in the technological development of heating systems require a significant correction of stating and solving typical technical and economic problems to design these systems, which, in turn, predetermines the transition to a new level of their methodological support [2]. The paper proposes a mathematical formulation of the problem of optimal development of heat sources and considers a methodological approach to solving it, including effective load distribution between heat sources, and calculation of the optimal heat network configuration, given the minimum environmental impact of heat sources.
\end{abstract}

\section{A methodological approach to optimization of heating systems}

The optimal expansion of heat sources in the stage of the heating system development implies the selection of sites, types and mix of equipment of the heat sources together with effective load distribution between them, and selection of an optimal configuration of the heat network connecting the heat sources and the consumer. The main specific features of the problem are its discreteness, integer nature, and nonlinear relationships. One way to solve this problem is to use an optimization method based on joint consideration of all possible combinations of heating system components with a wide variation in capacity, location and number of sources [3, 4], which is as follows:

In the first stage, the sites for the heat sources and optimal load distribution between them are sought. To solve the problems of the first stage, the methods of structure and parameter optimization, developed in Melentiev Energy Systems Institute SB RAS [5], are applied. They suggest building a redundant scheme of the heat network, creating a redundant set of sites for placement of heat sources and solving the optimization problem

\footnotetext{
*Corresponding author: edel@isem.irk.ru
} 
aimed at finding an effective solution for heat capacity and territorial location of the heat sources.

In the second stage, based on the solutions obtained in the first stage, a redundant scheme of the structure of heat sources is designed: the options that are redundant in terms of both the type of heat source (boiler room, CHP, etc.) and the mix of equipment (manufacturing companies, size, layout of the main equipment) are built. The structure is taken to mean the types, mix and location of equipment as well as its amount and capacity. Atmospheric pollution is assessed, and the assessment results can require a change in the initial distribution of loads between sources, or in their structure. Next, for each option of the heat source structure, the optimization problem is solved to choose a scheme and the optimal parameters of the heat network connecting the heat sources with the consumer. The total costs are calculated by heat source and heat network, the costs of the option are stored, and new heat source sites and distribution of loads are planned. The iterative process allows obtaining several options for the heating system development, comparing them and selecting an optimal one.

\section{A mathematical statement of the problem of optimal development of heat sources in heating systems}

The optimal development of heat sources in the heating systems is an independent problem, which can be part of other more complex tasks.

Mathematically, this problem can be written as follows. A set of sources $E$ in a populated area consists of subsets of existing $E_{1}$ and new $E_{2}$ heat sources. For each heat source $e \in E$, we form a set $M_{e}$, with its each component $m$ defining an option of reconstruction and/or modernization of an existing heat source or installation of a new heat source.

The objective function is a sum of costs determined by the mix, type and efficiency of the system components, USD:

$$
S=\sum_{e}^{E} s_{e} \cdot Q_{e}+S_{n e t}+\sum_{k}^{K} S_{k} \cdot F_{e k}-S_{\text {out }}^{e p s} \cdot W_{\text {out }}^{e p s}+S_{\text {in }}^{e p s} \cdot W_{\text {in }}^{e p s} \Rightarrow \min ,
$$

where $S$ - costs of the heating system, USD; $s_{e}$ - specific costs of the $e$-th source, $\mathrm{USD} / \mathrm{Gcal}(\mathrm{USD} / \mathrm{KW}) ; Q_{e}$ - heat generation by the $e$-th source, Gcal/year; $S_{n e t}$ - heat network costs, USD; $S_{k}$ - fine for exceeding the maximum permissible emission of the $k$ th substance, USD/t; $F_{e k}$ - gross emission of a harmful substance $k \in K$ from the $e$-th source, t/year; $S_{\text {in }}^{\text {eps }}$ - price of electricity purchase from electric power system, $\mathrm{USD} / \mathrm{KWh} ; S_{\text {out }}^{e p s}-$ price of selling electricity to electric power system, $\mathrm{USD} / \mathrm{kWh} ; W_{\text {in }}^{e p s}$ amount of electricity purchased from electric power system MWh/year; $W_{\text {out }}^{\text {eps }}-$ amount of electricity sold to electric power system, MWh/year.

The conditions and constraints are: Balance between heat production and consumption in an area, Gcal/year:

$$
Q^{\text {area }}=\sum_{e}^{E} Q_{e}
$$


Balance between electricity production and consumption, $\mathrm{MWh} /$ year:

$$
\sum_{e}^{E} W_{e}-W^{c i t y}-W_{o u t}^{\mathrm{eps}}+W_{\text {in }}^{\mathrm{eps}}=0
$$

where $Q^{\text {city }}$ - heat consumption in an area, Gcal/year; $W_{e}$ - electricity output from the $e$-th source, $\mathrm{MWh} /$ year; $W^{\text {city }}$ - electricity consumption in an area, MWh/year.

Condition for competition between the options of reconstruction and/or modernization of the existing heat source $e \in E_{1}$ :

$$
\sum_{m}^{M_{e}} V_{e}^{m}=1
$$

Condition for competition between the options of newly constructed heat sources $e \in E_{2}$ :

$$
\sum_{m}^{M_{e}} V_{e}^{m}=G_{e}
$$

where $V_{e}^{m}$ represents implementation/non-implementation of an option of the equipment mix $m \in M_{e}$ of heat source $e$ characterized by definite technical and economic indices; $G_{e}$ - auxiliary variable of Boolean type.

The protection of the atmosphere by the heating systems implies meeting: - the standards for maximum permissible emissions of harmful substances, $t /$ year:

$$
F_{e k} \leq F_{e k}^{\max }
$$

- the standards for maximum permissible concentrations of harmful substances during dispersion of these emissions, $\mathrm{mg} / \mathrm{m}^{3}$ :

$$
C_{k y}-\Delta C_{k y} \leq C_{k}^{\max }
$$

where $F_{e k}$ - gross emissions of harmful substance $k$ from the $e$-th heat source, $\mathrm{t} /$ year; $F_{e k}^{\max }$ - maximum permissible emissions of the $k$-th harmful substance determined by the calculation for the $e$-th source, t/year; $C_{k y}$ - calculated concentration of the $k$-th substance in the atmosphere at point $y, \mathrm{mg} / \mathrm{m}^{3} ; \Delta C_{k y}$ - a change in $C_{k y}$ owing to the measures for the atmosphere protection, $\mathrm{mg} / \mathrm{m}^{3} ; C_{k}^{\max }$ - maximum concentration of the $k$ th substance in the atmosphere, which is relatively safe for a human and environment (normally the assumed values of maximum permissible concentrations are established by law as a sanitary and hygienic standard), $\mathrm{mg} / \mathrm{m}^{3} ; y-$ a point from the set of points $Y_{k}$ of territorial dispersion of the $k$-th harmful substance.

Each option of the structure of the heat sources solves the optimization problem to select the parameters of heat networks. The objective function of this optimization problem is the minimum cost of their construction and operation under a given configuration: 


$$
\begin{aligned}
& S_{n e t}(\mathbf{d}, \mathbf{x}, \mathbf{H}, \mathbf{P})=\sum_{i \in I} S_{i}^{\mathrm{Pipe}}\left(d_{i}\right)+\sum_{i \in I_{\mathrm{HC}}} S_{i}^{\mathrm{PuS}}\left(H_{i}, x_{i}\right)+ \\
& +\sum_{i \in I} S_{i}^{\mathrm{El}}\left(x_{i}, d_{i}\right)+\sum_{i \in I} S_{i}^{\mathrm{HL}}\left(d_{i}\right)+\sum_{j \in J_{\mathrm{CON}}} S_{j}^{\mathrm{Co}}\left(P_{j}\right) \rightarrow \mathrm{min},
\end{aligned}
$$

where $S_{i}^{\text {Pipe }}-$ construction and operation costs of pipeline $i ; S_{i}^{\text {PuS }}-$ costs of pumping station construction and operation; $S_{i}^{\mathrm{El}}-$ cost of electricity for heat carrier pumping at pipeline $i ; S_{i}^{\mathrm{HL}}-$ cost of heat losses in pipeline $i ; S_{j}^{\mathrm{Co}}-$ cost of electricity used to deliver heat carrier to consumer $j ; I-$ a set of pipelines in heat network; $I_{\mathrm{PuS}} \subset I-$ a set of sections where the pumping stations are allowed to be installed or are installed; $J_{\mathrm{CON}}-$ a set of consumer nodes; $\mathbf{d}=\left(d_{1}, \ldots, d_{n}\right)^{\mathrm{T}}, \mathbf{x}=\left(x_{1}, \ldots, x_{n}\right)^{\mathrm{T}}$ and $\mathbf{H}=\left(H_{1}, \ldots, H_{n}\right)^{\mathrm{T}}-$ vectors of diameters, flow rates and pressure differences, respectively; $\mathbf{P}=\left(P_{1}, \ldots, P_{u}\right)^{\mathrm{T}}-$ vector of pressure at nodes.

Problem (1)-(8) is non-linear in nature, which, in particular, is caused by the presence of integer variables and non-linear relationships. A methodological approach based on the construction of redundant schemes developed both in Russia and abroad [1, 6, 7] proved to be quite effective when applied to the optimization of the structure of heat sources in the heating systems.

\section{Methods of constructing redundant schemes to select the structure of heat sources}

Design of a redundant scheme is a complex and important task, which is usually carried out manually. A P-graph approach $[9,10]$ was developed to build redundant schemes based on the graph theory. This approach is based on three specialized algorithms: MSG to generate maximum structure [11, 12], SSG to generate final structures $[11,13]$, and $\mathrm{ABB}$ to determine the optimal structure $[14,15]$ using the algorithm of nodes and branches. According to this approach, various options for the heat source equipment mix are considered in a single scheme that contains a finite number of components with their possible interconnections.

The redundant schemes can be built through the adaptation of a methodology of energy hubs [16]. This methodology is widely used to model integrated energy systems. In this case, the redundant scheme is formed as a set of interconnected structures of heat sources in the form of a network of energy hubs [17, 18].

The common feature of these two approaches is that technological models of the sources consist of three components [10,11]: 1) input flows of primary and converted energy carriers supplied directly from producers, or from a system of energy transportation infrastructure; 2) energy converters that ensure the transformation of certain types of energy carriers into other types of energy, or are responsible for changing physical parameters of the energy carriers; 3 ) the output flows of energy carriers directed to the energy loads of consumers. Apart from the energy carriers, the output flows of the heat source can be the emissions of harmful substances produced when burning fossil fuels. The main assumptions made in this approach include the following: 1) there are no losses in the structure of the heat source, except for conversion losses; 2) the modeled system is in a steady state; 3 ) the energy carrier flow is always directed from the inlet to the outlet. 
The software implementation based on the joint application of the two above-proposed approaches seems to be effective for the development of an approach to the construction and optimization of redundant schemes of the heat sources structure.

\section{Practical calculations}

The software proposed in the paper is intended for doing complex engineering tasks related to the development of heating systems. The software was used to carry out multivariate calculations for the heating system in the urban village of Magistralny in Kazansk-Lensk area, the Irkutsk region. The calculation results were employed to perform feasibility studies on optimal reconstruction of this heating system. The need to address the issues of the heating system development in this village is caused by rising heat loads and the necessity for the system reconstruction.

Currently, there is one Central boiler house operating in this village. In the future, new heat sources can be constructed at the sites of two previously existing boiler houses. The fuel supply options considered while planning the types and mix of equipment of the heat sources are: gas supply for heating purposes according to the planned conversion of the consumer to gas in the Irkutsk Region [19]; ORC-technology [20]); preservation of the existing fuel system oriented to burning brown coal. Combined options considering several various fuel types were also prepared. For each option of the heat source structure, the gross emissions of harmful substances were calculated. The redundant scheme of heat sources is presented in Fig. 1. Each of the seven demonstrated technological structures of the heat sources represents a set of options for their development.

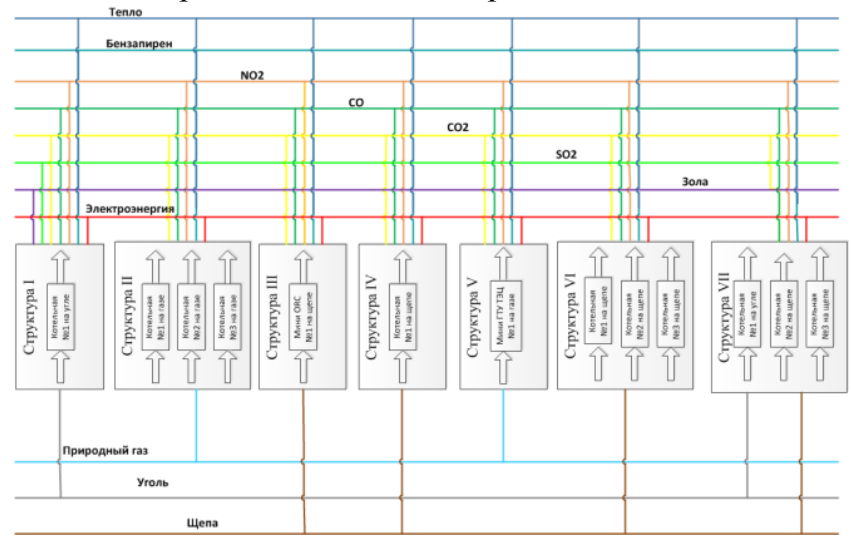

Fig. 1. A redundant scheme of heat sources.

The considered options of the heat source structure were compared in terms of their techno-economic indices and emissions of harmful substances with the help of the aboveproposed approach. The comparison allows us to obtain an optimal solution corresponding to option VI of the heat source structure (Fig.1).

This option proposes the installation of a boiler plant on wood chips with eight hot water boilers KVm-4.0 (manufactured by Baltkotlomash Ltd). The heat capacity of the boiler plant will be $27.5 \mathrm{Gcal} / \mathrm{h}$. It is more profitable, however, to buy electricity for the needs of the populated area from an external power system. Gross emissions of harmful substances in this option of the heat source structure are minimal, and in comparison with the base option (structure I) are: ash $-0.063 \%$ (0.27 t/year) $N O_{x}-86.6 \%(17.19 \mathrm{t} /$ year), $\mathrm{CO}_{2}-50 \%$ (28759.23 t/year), benzopyrene - 31.4\% (0.000000433 t/year). Discounted costs for the heat source will be $\$ 2.3$ million, for the heat networks $-\$ 1.48$ million. 


\section{Conclusion}

A mathematical statement of the optimization problem of the heat sources structure is proposed. This statement explicitly takes into account the conditions for competition between the heat source options, as well as the methodology of redundant schemes.

We have developed software for optimizing the structure of heat sources. The software makes it possible to successfully solve the problems of heating system development and reconstruction. The proposed software was tested on a real heating system.

The research was carried out under State Assignment, Project III.17.4.1 (reg. AAAA-A17117030310432-9) of the Fundamental Research of Siberian Branch of the Russian Academy of Sciences.

\section{References}

1. E.V. Sennova, V.G. Sidler, Mathematical modeling and optimization of developing heating systems (Nauka, Novosibirsk, Russia, 1987)

2. N.I. Voropai, V.A. Stennikov, E.A. Barakhtenko et al., Russia's Energy Sector in the 21st Century. Innovative Development and Management, 47 (2015)

3. L.S. Khrilev, I.A. Smirnov, Optimization of cogeneration systems and district heating (Energy, Moscow, Russia, 1978)

4. A.I. Yufa, D.R. Nosulko, Complex optimization of heat supply ("Tekhnika", Kiev, Ukraine, 1988)

5. A.P. Merenkov, E.V. Sennova, S.V. Sumarokov et al., Mathematical modeling and optimization of heat, water, oil and gas systems (Nauka, Novosibirsk, Russia, 1992)

6. N.N. Merenkova, E.V. Sennova, V.A. Stennikov, Electronic modeling, 6, 76 (1982)

7. S. Mitra, L. Sun, I.E. Grossmann, Energy, 54, 194 (2013)

8. B. Bahl, M. Hennen, M. Lampe, P. Voll, A. Bardow, Resource Efficiency of Processing Plants, 373 (2018)

9. H. L. Lam, Current Opinion in Chemical Engineering, 2(4), 475 (2013)

10. F. Friedler, K. Tarjan, Y. W. Huang, L. T. Fan, Chemical Engineering Science, 47(8), 1973 (1992)

11. F. Friedler, K. Tarjan, Y. Huang and L. Fan, Comput. Chem. Eng., 16(1), 313 (1992)

12. F. Friedler, K. Tarjan, Y. Huang, and L. Fan, Comput. Chem. Eng., 17(9), 929 (1993)

13. F. Friedler, J. B. Varga, L.T. Fan, Chemical Engineering Science, 50(11), 1755 (1995)

14. F. Friedler, J. B. Varga, E. Feher, L. T. Fan, In State of the Art in Global Optimization Springer US, 609 (1996)

15. P. Voll, C. Klaffke, M. Hennen, and A. Bardow, Energy, 50, 374 (2013)

16. M. Mohammadi, Y. Noorollahi, B. Mohammadi-ivatloo, H. Yousefi, A review. Renewable and Sustainable Energy Reviews, 80, 1512 (2017)

17. M. Almassalkhi, I. Hiskens, 17th Power System Computation, Conf. Stockholm, Sweden (2011)

18. Y. Wang, J. Cheng, N. Zhang, C. Kang, Applied Energy, 211, 705 (2018)

19. Adjustment of the General Scheme of Gas Supply and Conversion to Gas of Consumers in the Irkutsk Region (Gazprom, Moscow, Russia, 2009)

20. A.N. Blinov, S.E. Peredery, LespromInform, 8, 136 (2014) 